\title{
Professores Políticos em Sergipe: inserção profissional e carreiras políticas
}

Taís Cristina S. Figueiredo ${ }^{1}$

\section{Resumo}

Este artigo foi desenvolvido a partir dos resultados de uma pesquisa em que busquei apreender as modalidades de carreira política de professores no estado de Sergipe, a partir da análise dos itinerários dos políticos eleitos que se definiram como professores nas legislativas do ano de 2010 e nas eleições para Câmara de Vereadores da Capital do Estado, Aracaju, no ano de 2008. Desta forma, o artigo apresenta um panorama da profissionalização docente e sua relação com a política; a participação dos professores nas eleições em Sergipe, a origem familiar e os aspectos de socialização dos professores eleitos, e as modalidades de carreiras políticas de sete professores estudados.

Palavras-chave: Professores; política; carreira; poder.

\section{Political Teachers in Sergipe: professional insertion and political careers}

\begin{abstract}
This article was developed from the results of my master's degree, in which I sought to seize the political career of teachers in the State of Sergipe (Brazil), from the analysis of itineraries of elected politicians that if defined as teachers in the legislative year of 2010, and in elections to the City Council of the Capital of the State, Aracaju in the year 2008. So, the article presents an overview of teacher professionalization and its relationship
\end{abstract}

1 Mestre em Antropologia pela Universidade Federal de Sergipe. e-mail: taissamora@ oi.com.br. 
with politics; the teachers ' participation in the elections in Sergipe, the family origin and the socialization aspects of elected professors, and the political careers of seven teachers.

Keywords: Teachers; politics; career; power.

\section{Introdução}

Os estudos sobre militância, engajamento, profissionalização e participação política ${ }^{2}$ têm assumido uma grande importância nas Ciências Sociais, nas últimas décadas, tanto num contexto nacional quanto internacional. As pesquisas realizadas atualmente no Brasil são baseadas em universos empíricos que não se restringem apenas ao momento eleitoral, isto é, incluem as relações entre o momento pré-eleitoral, o eleitoral e o pós-eleitoral. Tais pesquisas buscam compreender as mais variadas formas de relações e investimentos (sociais, profissionais e militantes) que se manifestam nos diversos espaços em que a política se desenrola.

Este estudo situa-se no âmbito das discussões sobre as condições de profissionalização política no Brasil. Entretanto, mais especificamente, insere-se em vertentes de estudo que tomam a condição profissional como base para a elaboração de carreiras na esfera política, e se enquadra numa perspectiva de análise sobre as estruturas e as relações nos espaços de poder, neste caso específico sobre a relação entre uma categoria profissional, a dos professores, e a política e apresenta um estudo sobre os sete professores que assumiram cargos eletivos em 2008, como vereadores e em 2010, como deputados.

O tema da pesquisa tratou dos condicionantes sociais e culturais implicados no processo de politização desses professores e par- 
te de uma análise em que buscou-se identificar as competências consideradas legítimas para que estes políticos pleiteassem cargos eletivos. Como sugere Bourdieu (1998), só quem possui uma competência específica pode entrar com alguma possibilidade de sucesso no jogo político, pois um modo de pensamento e ação é exigido na participação do campo político, em que se espera uma preparação especial. Isto significa uma aprendizagem necessária para se conquistar tais saberes, bem como, o domínio de uma linguagem e de uma retórica próprias. Saberes adquiridos que são considerados essenciais ao exercício de atividades da política, que ocupam um lugar central nos processos de entrada e engajamento no campo dos embates políticos, incluindo-se aí o eleitoral. Verificou-se também as práticas e habilidades que possibilitaram aos professores a aquisição de saberes e que puderam ser reconvertidas em competências políticas, entendidas aqui como capital militante (MATONTI \& POUPEAU, 2004).

Através de uma perspectiva interpretativa e comparativa de análises sobre as habilidades, competências, saberes e experiências adquiridas nos percursos sociais e políticos, a antropóloga Karina Kuschnir (1999) sugere que se pode compreender não só as formas de representações e práticas dos sujeitos na política, como se pode também apreender muito sobre o universo simbólico da política e suas influências sobre a sociedade. A autora descreve a atuação dos políticos como negociadores $d a$ realidade, traduzindo e interpretando códigos diversos, com habilidades de dialogar com diferentes níveis de cultura, códigos e valores (KUSCHNIR, 1999, p.16). É a partir de abordagens interdisciplinares, do diálogo da Antropologia com outras disciplinas e da adoção de uma perspectiva comparativa, que se pode compreender não só as representações e as práticas da política num grupo específico, mas também suas relações mais amplas com a sociedade. Segundo Kuschnir A antropologia pode contribuir nesse debate porque sua principal tarefa é estudar não o que a política deve ser, mas o que ela é para um determinado grupo, em um contexto histórico e social específico. (KUSCHNIR, 2007, p. 165). 
Estudos recentes ${ }^{3}$ têm apresentado diferentes resultados que abordam e relacionam a militância e o exercício profissional com a política eleitoral. Tais estudos buscam apreender as modalidades de articulação entre a atuação profissional e o engajamento político. Através deles, é possível saber que a possibilidade de se ocupar posições em outras esferas sociais, além da profissional, depende da posição social do profissional e do acúmulo de recursos sociais que ele dispõe. Tem-se percebido que a mobilização coletiva passou a ser uma forma de se ampliarem as possibilidades de investimentos que percorrem o espaço político, permitindo relacionar profissão, engajamento e participação política, o que possibilita adquirir um capital militante, aumentando o capital político e também profissional dos atores envolvidos (PETRARCA, 2011).

Ao trabalhar com uma determinada categoria profissional, a de professores, com o intuito de apreender o universo simbólico e prático nos quais os atores estão inseridos, foi analisado as múltiplas formas adotadas de engajamento e militância, que resultam como condicionantes da inserção dos professores no universo da política. Para tanto foi preciso pensar, como sugere Coradini, sob o ângulo das relações entre a profissão de professor e a militância partidária:

(...) as variações nas modalidades de se relacionar com a profissão, com sua representação sindical ou corporativa, com outras modalidades de militância e, consequentemente, com a própria entrada na carreira política são extremante amplas, o que não impede o estabelecimento de alguns padrões. Nesses padrões, no caso dos professores, os principais condicionantes são o tempo dedicado à ocupação no magistério strictu senso à representação sindical ou a outras modalidades de militância, à ocupação de cargos de "confiança" e, por fim, à conquista e exercício de cargos eletivos. (CORADINI, 1995, p. 134/135). 
Embora seguindo a perspectiva adotada por Coradini (1995), durante a pesquisa foi preciso colocar sob suspeita os condicionantes definidos pelo autor. Isto porque alguns dos professores estudados não passaram por todos os padrões referidos. 0 que implicou, para o caso, uma análise empírica que permitisse ampliar as percepções sobre as nuanças de reivindicação da condição de professor por parte dos candidatos e a relação com seus itinerários de vida.

0 artigo está dividido em quatro sessões: o primeiro apresenta um panorama sobre a profissionalização docente no Brasil e em Sergipe e sua relação com a política; o segundo apresenta a participação dos professores na política eletiva em Sergipe nas eleições de 2008 e 2010; o terceiro aponta a origem familiar e as formas de socialização dos políticos e o quarto as modalidades de carreiras políticas dos sete professores/políticos eleitos nas duas eleições.

\section{A Profissionalização Docente e a Política}

Com o intuito de delinear o processo de reconhecimento da atividade docente no Brasil, mesmo que brevemente, abordo, neste momento, aspectos relacionados à profissionalização do magistério, sob o viés da relação com a política. Muitos trabalhos já foram escritos sobre a "história da atividade docente e sua profissionalização", principalmente Brzezinski (2002), Nóvoa (1999), Romanelli (2003), Saviani (2004) e Tanuri (2000). Estes autores destacaram o processo de desenvolvimento histórico da escola e da atividade docente, enfatizando questões, como: 1) as transformações da escola durante o século vinte e o impacto sobre a constituição da profissão (SAVIANI, 2004); 2) o desenvolvimento da profissão (NÓVOA, 1999), a formação e qualificação dos professores como uma questão de fortalecimento da profissão (TANURI, 2000); e 3) os desdobramentos da atuação associativa e sindical e o amadurecimento da identidade profissional (BRZEZINSKI, 2002). 
Para Nóvoa (1999), o processo de profissionalização da atividade docente foi destacado por uma evolução linear e inflexível e a afirmação profissional dos professores foi, e ainda é, um caminho cheio de conflitos e lutas, pois o campo educativo está ocupado por vários atores que se sentem ameaçados com a consolidação da profissão.

Embora o percurso da atividade docente seja caracterizado por vários interesses que não se reduzem aos dos professores, os estudos dos autores acima demonstram que a educação brasileira e o reconhecimento profissional do magistério foram ganhando espaço durante o século vinte. A atividade docente está presente na sociedade brasileira, pelo menos desde o século dezoito, mas só foi se constituindo rumo à profissionalização a partir do momento em que houve a expansão dos sistemas escolares no Brasil e sua regulamentação e controle por parte do Estado se tornou mais efetiva. No decorrer da década de 20, do século passado, o trabalho do professor passou a ser entendido como um conjunto de normas e conhecimentos técnicos e teóricos que caracterizavam o professor profissional.

Nóvoa (1999) apresenta um modelo de análise sobre o processo histórico da profissionalização dos professores, que aponta quatro etapas de seu desenvolvimento, enquanto estatuto social e econômico. 0 primeiro momento seria o que prevaleceu com o exercício da atividade docente a tempo inteiro; o segundo, o estabelecimento de um suporte legal para o exercício da atividade; o terceiro, o da criação de instituições específicas para a formação de professores; e o quarto momento, o da constituição de associações profissionais e sindicatos. Segundo Nóvoa (1999), tais momentos não devem ser lidos numa perspectiva sequencial rígida, mas possibilitam um entendimento processual sobre o desenvolvimento da profissão durante o percurso do século vinte.

Além de o professor profissional ocupar um determinado lugar na divisão social do trabalho a partir dos anos vinte, com um 
conjunto de habilidades profissionais características da profissão e que se perpetuaram ao longo dos anos, Brzezinski (2002) destaca que outros elementos estruturaram o profissionalismo docente. São eles: competência, licença, vocação, independência e autoregulação (ENGUITA apud BRZEZINSKI, 2002, p. 14). Nesta perspectiva, a atividade docente é caracterizada como composta por atividades especializadas que possuem um conjunto de saberes específicos, códigos e normas próprias a um determinado grupo profissional.

Com a profissionalização, passaram a ser valorizados os domínios de conhecimento específico de sua área e os saberes pedagógicos formais. Não devemos esquecer que teorias, competências e saberes passam por processos de alteração, surgindo novas teorias, novas competências e novos saberes que são adquiridos e cobrados. Isto resulta em mudanças nas práticas pedagógicas que, muitas vezes, confundem o conhecimento educacional com as teorias dos processos pedagógicos, os quais passam a se resignificar de acordo com o momento que a sociedade vive. Sendo assim, a profissionalização do professor pode ser compreendida como um processo de construção histórica que varia com o contexto social que lhe dá significação. Segundo Nóvoa (1999), a caracterização do professor profissional se dá tanto através de saberes e competências desenvolvidas e que se completam num processo de socialização centrado na escola e num dado contexto local, quanto pela assimilação de normas e valores institucionais que regulam a atividade e o desempenho do papel do professor entre os seus pares.

Segundo Brzezinski (2002) é possível compreender o surgimento de um senso de identidade profissional entre os professores à medida que os mesmos se envolvem em discussões sobre o contexto educacional e escolar, que acabam por enfatizar algumas orientações e entendimentos práticos e teóricos sobre o papel do professor na educação. Esta politização de entendimentos leva, muitas vezes, os professores aos movimentos sociais. Se- 
gundo a autora, nas associações e sindicatos da categoria profissional se encontram os espaços mais importantes para a construção de um sentimento de identificação profissional, embora seja possível perceber a complexidade dos contornos em torno dos posicionamentos dos professores sobre a educação. Esses espaços de mobilização, da escola às associações e aos sindicatos, possibilitam que as relações sejam tecidas por meio de intensas mediações, como momentos de negociação e construção de um coletivo de interesses.

A observação de Brzezinski (2002) sobre a participação dos professores em movimentos sociais é da mesma forma entendida por Ribeiro (1984), quando enfatiza a ideia de que o magistério, enquanto atividade que se realiza objetivamente, é político, pois se insere diretamente na "luta pela socialização da cultura", e ao mesmo tempo é politizante porque é no exercício prático da docência que os professores se formam politicamente, descobrindo a exigência de se atingir níveis de organização capazes de articular o conjunto da categoria com os interesses de outros grupos sociais.

A partir de meados do século vinte, o surgimento das associações e sindicatos, e o envolvimento em outros movimentos sociais, propiciaram aos profissionais da educação, através da manifestação coletiva, o reconhecimento social da categoria e de suas reivindicações por melhores condições de trabalho e ensino. Tais reivindicações se tornaram públicas através de movimentos grevistas e de negociações que procuraram legitimar as ações das instituições representativas em nome dos professores, abrindo caminhos e possibilidades para se inserirem no "jogo político".

Em Sergipe, o processo de profissionalização docente seguiu caminho semelhante ao do restante do Brasil. Primeiramente, com o surgimento do Ensino Normal, a partir de 1870, e um pouco mais tarde, no início do século vinte, através de um movimento 
representado por intelectuais com responsabilidade administrativa sobre a educação formal que renovou o modelo educacional e os modos de ingresso na atividade docente através da estruturação da escola pública, gratuita e laica, cada vez mais controlada pelo Estado. É importante lembrar que para além de um movimento reproduzido nacionalmente, o início do processo de modernização pedagógica foi influenciado por um fenômeno que anos antes teve sua origem nos principais países europeus e nos Estados Unidos.

No decorrer da década de 1910, o curso normal para a preparação de professores passou a ter a duração de quatro anos, prédio próprio, e a inclusão de novas disciplinas (como trabalhos manuais, ginástica, música e desenho), o que significava o aumento de exigências quanto às habilidades dos professores. Segundo Silva (2008), essa nova configuração da Escola Normal concedeu ao ensino em Sergipe uma característica própria e legitimidade na formação de professores, e os resultados seriam vistos nas décadas seguintes, influenciando outras etapas do processo de profissionalização dos professores do Estado. A institucionalização da Escola Normal, neste período, esteve associada a um conjunto de ações do Estado, incluindo um suporte legal para o exercício do magistério público, que conferia aos titulados reconhecimento profissional e status social e, ao mesmo tempo, definia o perfil do novo professor. 0 domínio de um conteúdo e de um método credenciava o professor para o exercício da profissão. Para Silva (2008) a profissão docente em Sergipe se constituiu em torno do diploma, além de outros dispositivos pessoais que definiam o perfil dos interessados a ingressar no magistério público. Segundo Silva,

A tutela do Estado sobre o professorado, transformado-o em um funcionário público, favorece uma maior afirmação autônoma da profissão docente, amparada por uma legislação que estrutura a carreira profissional do magistério, sob 
a forma de condições, vantagens, deveres e punições, como as estabelecidas para os interessados em ingressar e permanecer no magistério publico primário de Sergipe. (SILVA, 2008, p. 108)

O primeiro concurso geral do Estado para o magistério aconteceu em 1976. Estavam disponíveis vagas para todos os níveis de ensino, e os professores já contratados no Estado ficaram condicionados a sua aprovação no concurso para permanecerem nos cargos, caso contrário o contrato seria reincidido (MENEZES, 2011). No ano de 1977, foi fundada a primeira organização dos trabalhadores da Educação em Sergipe, criada a partir da mobilização de um grupo de educadores que instituiu a Associação dos Profissionais do Magistério de Sergipe (APMESE). Esta organização se manteve até 1988, ano que passou a ser denominado Sindicato dos Trabalhadores da Educação de Sergipe (SINTESE).

Neste caso, entendo que a comunidade associativa foi, e ainda é, um espaço de representabilidade e legitimidade política das discussões e ações que conferiram ao professor alguma posição de credibilidade, não apenas por consolidar a ideia de categoria profissional, do ponto de vista formal, mas também pelo reconhecimento público da profissão. Um movimento que se deu com o intuito de politização da categoria e que estabeleceu o professor enquanto um sujeito coletivo, que passou a adotar um discurso de profissão e ter uma expressão de representação social com maior visibilidade a partir dos anos oitenta.

Os Professores/Políticos em Sergipe: as eleições de 2008 e 2010

No Brasil, pouco se estudou sobre a relação entre professores e seu ingresso e envolvimento na política eleitoral. Embora o magistério não pertença às "profissões de elite" do país e aos profissionais da "elite política", a categoria é vista como uma das 
profissões em que os brasileiros mais confiam, ocupando o terceiro lugar em um ranking sobre as profissões mais confiáveis, no ano de 2010. Em tal pesquisa, 87\% dos entrevistados afirmaram confiar no profissional professor ${ }^{4}$. Com tal resultado é possível inferir que há certo "reconhecimento" e "confiança" da sociedade quanto aos profissionais da categoria. Segundo a Estatística da Educação Básica, sobre ano de 2008, os professores totalizavam 1.988.161 pessoas em atividade no Ensino Básico, no Brasil, e 23.381 professores em atividade no Estado de Sergipe $^{5}$. Tais dados correlacionados com os dados do IBGE sobre ocupação da população ativa no Brasil, que é de 92.395.000, e em Sergipe, de 989.000, indicam que a ocupação "professor", no Brasil, é de aproximadamente $1.8 \%$, e em Sergipe, de $2.3 \%{ }^{6}$ do total das ocupações

Observo que do universo de 158 opções de classificação sobre a ocupação, que o candidatos tem a sua disposição para escolher no momento do registro de sua inscrição, o número de candidatos que se declararam professores é relativamente grande se levarmos em comparação o total de ocupações disponíveis. Tal resultado fortalece a ideia do quanto é interessante que se desenvolvam pesquisas abrangendo este tema, já que a participação de professores em eleições é recorrente, a profissão é significativa no contexto das ocupações em geral e os professores constituem um número significativo de pessoas envolvidas com a política, como o exemplo abaixo.

4 Estas informações estão disponíveis no site http://guiadoestudante.abril.com.br/ vestibular-enem/brasileiro-acredita-mais-professores-menos-politicos-veja-ranking-profissoes-mais-confiaveis-572968.shtml (Acessado em 30 de maio de 2011).

5 Cf. http://portal.inep.gov.br/basica-censo-escolar-sinopse-sinopse (Acessado em 22 de agosto de 2012)

6 Cf. http://www.ibge.gov.br/home/estatistica/populacao/trabalhoerendimento/ pnad2009/pnad sintese 2009.pdf (Acessado em 22 de agosto de 2012) 
Quadro 1 - Números de Candidatos nas Eleições Municipais em Sergipe (2004, 2008, 2012)

\begin{tabular}{|c|c|c|c|}
\hline Ano & $\begin{array}{c}\text { Total de } \\
\text { Candidatos }\end{array}$ & $\begin{array}{c}\text { Professores } \\
\text { Candidatos }\end{array}$ & $\begin{array}{c}\text { \% em relação às } \\
\text { ocupações }\end{array}$ \\
\hline 2004 & 4664 & 359 & $7,7 \%$ \\
\hline 2008 & 4633 & 347 & $7,5 \%$ \\
\hline 2012 & 5779 & 346 & $6 \%$ \\
\hline
\end{tabular}

Fonte: Tribunal Superior Eleitoral'.

Os dados sobre o número de professores que assumiram cargos eletivos em 2008, no estado em Sergipe, trazem informações sobre a presença dos professores tanto na disputa e eleição em cargos executivos, quanto legislativos, e em diferentes cidades do Estado.

O estado de Sergipe é formado por 75 municípios e, com o resultado das eleições de 2008, dos 12 professores que foram candidatos $50 \%$ deles foram eleitos, o que resultou na presença de tais profissionais em 8\% das prefeituras do Estado. Nas Câmaras Municipais, a categoria também se fizera representar de forma significativa. Em 8 municípios, foram dois professores eleitos em cada um. Em 27 municípios, foi eleito um professor em cada Câmara ${ }^{8}$.

Os professores estiveram presentes em mais da metade das disputas eleitorais dos municípios de Sergipe e foram eleitos como vereadores em 46,8\% das câmaras municipais, em 2008. Tais professores estão presentes nas mais distintas regiões e municípios do Estado, às vezes como prefeitos outras como vereadores. É importante destacar para o caso deste estudo, que a Capital, Aracaju, elegeu dois professores e que foi um dos municípios com mais candidatos com esta ocupação nas eleições de 2008.

7 Todos os quadros no decorrer desta dissertação cuja fonte é o TSE, foram elaborados a partir de informações do endereço oficial do órgão na internet.

8 Os municípios onde os professores foram eleitos prefeitos são: Cristinápolis, Cumbe, Laranjeiras, Muribeca, Simão Dias e Umbauba. 
Em Aracaju aproximadamente 1\% dos candidatos que se declararam professores foi eleito ${ }^{9}$, o que significa que além de haver uma concentração de candidatos professores na Capital, houve também uma disputa maior entre eles para o ingresso à Câmara, embora representem números absolutos maiores que no restante do Estado.

É preciso considerar que Aracaju centraliza a vida econômica, cultural e política do Estado, possui a maior população e é onde se concentra a maior oferta de escolas privadas e públicas, a maior oferta de Ensino Superior para formação de professores, além do maior número de sindicatos e associações de professores, tanto do próprio município, quanto da representação sindical estadual.

Os indicadores justificam o fato da concentração de professores envolvidos na política eletiva estarem concentrados em Aracaju, porém isto não garante um número maior de candidatos eleitos do que em outros municípios. 0 sucesso eleitoral dos candidatos, independente da categoria profissional, vai depender de vários elementos construídos no decorrer de seus itinerários, pois recorrer somente à profissão não basta para se garantir o envolvimento e o sucesso na política.

Nas eleições para governo e legislativo só se elegeram professores para os cargos de Deputado Estadual e Deputado Federal, mesmo com professores participando do pleito para todos os cargos. Dos 4 candidatos a Deputado Federal que se declararam professores 1 foi eleito, e dos 8 candidatos a Deputado Estadual 4 foram eleitos. A proporção de candidatos e de eleitos que declararam esta ocupação foi bem mais reduzida do que no caso das eleições municipais, embora a presença dos professores te- 
nha se mostrado proporcionalmente mais relevante para a Assembleia Estadual. Neste caso, 50\% dos candidatos professores obtiveram sucesso eleitoral para o cargo, o que comparado com as outras ocupações coloca os professores entre uma das profissões numericamente mais bem representadas na Assembleia Legislativa de Sergipe.

Os professores estão entre as quatro ocupações com maior representatividade na Assembleia ${ }^{10}$, juntamente com a primeira posição dos que declararam ter por ocupação a atividade de deputados ou vereadores. Em seguida, temos os advogados e médicos ocupando ambos a segunda posição ${ }^{11}$. Esta situação confirma os dados apresentados pelo estudo de Rodrigues (2006), para quem os professores formam um grupo profissional ascendente na política eletiva brasileira, principalmente nas Câmaras Legislativas.

Diversos estudos ${ }^{12}$ que abordam a relação entre profissão e política demonstram que uma dada carreira profissional não garante a conquista de cargos eletivos. Vários recursos e investimentos são necessários e mobilizados para adquirir os conhecimentos e os saberes que possibilitam a entrada no jogo político.

$10 \mathrm{Na}$ legislatura anterior, $16^{\circ}$. eleita em 2006, o grupo de profissionais que declararam sua ocupação professor também ocupava a primeira posição, eram quatro políticos professores, em seguida vinha os médicos, advogados, empresários e deputados, com três representantes cada um, e na terceira posição estavam os administradores e engenheiros, com dois representantes cada.

11 Os deputados estaduais eleitos em 2010 que declaram suas ocupações como Deputados e Vereadores, antes de assumirem cargos eletivos tinham suas ocupações declaradas em: administrador outros, estudante, bolsita ou assemelhados e industriário.

12 Coradini (2006, 2001), Petrarca (2007), Rodrigues (2006). 


\section{Taís Cristina S. Figueiredo}

Segundo Rodrigues:

A representação política, nas democracias, é tarefa dos políticos, de um corpo de profissionais que, do ponto de vista psicológico individual, possui certas habilidades e ambições que não estão ao alcance ou não são partilhadas pelos cidadãos comuns. Do ponto de vista social, os que entram na política vêm geralmente de certos círculos profissionais e familiares que proporcionam uma socialização política informal desde muito cedo e que desenvolvem habilidades especiais para a entrada, permanência e ascensão nos variados escalões do sistema de poder. (RODRIGUES, 2006, p. 25)

Seguindo tal raciocínio, há atividades profissionais que associadas a outros condicionantes facilitam a entrada na carreira política. No caso dos professores, a questão parece carrear muitas singularidades e talvez não haja um padrão absoluto e definitivo para o caso. Diferentes socializações familiares e contextos sociais podem influenciar no percurso das escolhas e das oportunidades de envolvimento com a política.

A literatura francesa contribui com tal debate por apresentar algumas noções importantes quanto as relações entre classe, profissão e modalidades de inserção política. Dogan (1999) defende a importância da profissão anterior para se entender a inserção na política, apontando as profissões que possuem mais "afinidades" com a política. A profissão de professor é descrita por ele como possuindo uma certa vantagem pelo domínio da oratória que os professores desenvolvem na profissão. De certa maneira é possível concordar com sua colocação, porém, no Brasil, a realidade quanto às profissões e a inserção na carreira política é um tanto singular, pois a profissão professor não é classificada, ou não era, como sendo uma profissão própria da "classe política" ou da "elite política" no país, bem como nunca teve tanta representabilidade e legitimidade como na França. 
Rodrigues (2006), em sua pesquisa sobre a mudança socioprofissional na Câmara de Deputados no Legislativo Federal, investigou as alterações ocorridas no perfil das origens sociais dos políticos comparando as $51^{\circ}$ (1998) e 52ำ legislatura (2002), e detectou significativas mudanças, sugerindo uma "popularização" da Câmara. Ou seja, os parlamentares que ingressaram no legislativo no ano de 2002 não vieram, em igual número, das classes com maior poder econômico e das elites tradicionais, como na legislatura anterior. $\mathrm{O}$ autor aponta que foi em tal momento que os professores passaram a fazer parte do quarto maior grupo de profissões presentes na Câmara, sugerindo que o quadro de popularização foi um dos responsáveis por tal transformação.

Marenco \& Serna (2007) destacam algumas mudanças em relação às profissões que vivem "para a política", pois identificaram, em seus estudos sobre as posições sociais de origem dos políticos na Câmara dos Deputados do Brasil, que há uma diminuição na participação de profissões liberais (como advogados e médicos) e uma crescente participação de profissões ligadas à educação e ao sindicalismo. Os autores sugerem que se um candidato dispõe de recursos "próprios", como prestígio, renda e relações estabelecidas na ocupação profissional, ele não depende do consentimento partidário, passando a desconsiderá-lo com menor risco para o ingresso ou a continuidade em sua carreira (MARENCO \& SERNA, 2007, p. 109).

A atividade profissional tem sido destacada pela literatura, como recurso para inserção de novas pessoas na política. Entretanto, a relação entre profissão e política depende, de um lado, da forma como o exercício profissional possibilita o acesso a certas posições e recursos sociais que podem ser reconvertidos em recurso políticos (PETRARCA, 2007, p. 178). A atuação profissional em secretarias de educação, por exemplo, possibilita que a pessoa tenha visibilidade e proximidade com o universo político. No entanto, destaco que, em geral, ocupar funções em secretarias e outros 
cargos de "indicação" já poderia ser o resultado de competências acumuladas na militância das carreiras profissionais.

É importante entender o exercício da profissão (a de professor) e sua relação com a comunidade escolar como forma de sociabilidade e visibilidade, pois a escola possibilita uma ampla rede de relações onde vários atores estão envolvidos: alunos, professores, outros profissionais da escola e as famílias dos alunos. A escola também possibilita aos professores a alternativa de se envolverem com funções ligadas à administração escolar, associações e sindicatos da categoria, o que posteriormente pode significar a ascensão política, seja através de cargos de indicação ou cargos eletivos. Em alguns casos, a relação do professor com a escola pode estar totalmente voltada à política, já que a profissão concede ao profissional a viabilidade de perceber tensões e interesses que estão presentes no espaço escolar. Tal contexto permite que o professor ministre aulas, mas também que exerça uma função politizadora em um espaço de significativa socialização de indivíduos.

Através dos itinerários dos professores que assumiram cargos eletivos em 2008 e 2010 procurei verificar como se deu a atuação desses profissionais no magistério, no período anterior as suas atividades desempenhadas em cargos de indicação política ou eletiva, procurando compreender como aconteceu o processo de ascensão profissional (cargos de diretorias, direção escolar e secretarias) e aquisição de competências específicas da política até chegarem aos cargos eletivos.

A partir da análise do percurso profissional de cada professor eleito foi possível perceber que o primeiro contato com a atividade docente, o tempo de atuação no magistério e a ascensão profissional se apresentaram de forma singular em cada caso, o que não impediu perceber a característica de alguns padrões, pois foi possível notar semelhanças em seus percursos profissionais, embora com rupturas e particularidades. A pesquisa re- 
velou que os sete professores estudados estiveram envolvidos de algum modo com a profissão, quando pensaram ou se envolveram com a política. Parte da socialização destes políticos se deu atuando profissionalmente com a educação voltada para o Ensino Básico, assim como foi em distintos momentos entre as décadas de setenta e noventa, em que realizaram suas formações profissionais em licenciaturas em Instituições Públicas Federais, com exceção de uma única professora. Isto implica dizer que por diferentes caminhos a carreira docente serviu de algum modo para aquisição de saberes que contribuíram para atuação na política.

\section{Origem Familiar e Aspectos de Socialização dos professores/políticos}

A origem familiar e a formação escolar são muito enfatizadas nos estudos sobre dirigentes políticos. Desta forma, apresento alguns aspectos da vida dos professores eleitos vereadores de Aracaju, em 2008, e os professores eleitos deputados estaduais e federais nas eleições de 2010, em Sergipe, ressaltando características de sua socialização familiar e escolar.

Ressalto que os sete políticos (2vereadores, 4 deputados estaduais e 1 deputado federal) declararam em sua ficha de candidato no TSE a ocupação de professores. Todos têm curso superior em alguma licenciatura. Três deles são formados em Pedagogia, uma em Geografia, e os três políticos do sexo masculino são formados em licenciaturas em Construção Civil, em Química e em Biologia, o que lhes permitiram também a atuação em outras atividades técnicas. Tais dados são interessantes para se refletir sobre a relação entre origem social e formação escolar dos mesmos, ou, ainda, coligindo com outras informações, como, por exemplo, a experiência profissional e a participação política, seja ela eletiva ou não. 
Foi importante observar o itinerário individual dos professores em questão, pois através deles foi possível analisar como aconteceu a obtenção de conhecimentos próprios, tanto da esfera profissional, quanto da esfera política, que puderam ser convertidos em recursos característicos do jogo político. As nuanças de cada itinerário podem contribuíram para se pensar como os atores acionaram os recursos adquiridos em contextos sociais específicos, que permitiram expandir suas redes sociais e que possibilitam ampliar seu capital militante.

A origem familiar dos políticos estudados não se apresenta de forma homogênea, porém, a maioria deles diz ser oriundo de famílias humildes, sem muitos recursos financeiros e com pais pouco escolarizados. Alguns deles relataram que desde muito cedo, ainda enquanto realizavam o Ensino Fundamental, começaram a trabalhar para ajudar nas despesas domésticas. $\mathrm{Na}$ maioria dos casos, cresceram em bairros populares de Aracaju (Cirurgia, Santo Antônio, José Conrado Araújo, Siqueira Campos), sendo que em dois casos cresceram em bairros mais centrais, localidades caracterizadas como áreas privilegiadas.

A formação de Ensino Básico desses políticos se deu em grandes escolas públicas em Aracaju e, em um dos casos, em Itabaiana. As escolas que eles frequentaram foram importantes espaços de socialização, pois todas têm uma certa visibilidade e reconhecimento no Estado. Destaco que a maioria deles realizou o Ensino Básico há mais de trinta anos, por volta dos anos setenta, momento em que a escola pública tinha maior prestígio que nas últimas duas décadas. Um Deputado Estadual destacou em entrevista que, no período em que estudou no Colégio Atheneu, "figuras" importantes da cena política de Aracaju já haviam passado pelo Colégio e que o "atual vice-governador de Sergipe" também fora aluno no mesmo período que ele. Não apenas o Colégio Atheneu, mas outras escolas públicas, em que esses políticos estudaram, tiveram prestígio semelhante, por exemplo, o Instituto de Educação Rui Barbosa foi referência na formação 
de professores, a Escola Técnica Federal foi excelência na educação técnica profissional, o Colégio Estadual Presidente Castelo Branco foi uma grande escola e agregou alunos oriundos de nove bairros de Aracaju, e o Colégio Estadual Murilo Braga, em Itabaiana, foi uma das maiores escolas do interior do Estado.

Além do itinerário escolar, outro aspecto importante é destacar as principais disposições ao envolvimento associativo e a participação política dos entrevistados. Tais disposições se constituíram de elementos embasados na socialização familiar e escolar como, por exemplo, a presença de políticos na família e ou de familiares interessados em política. Uma Deputada Estadual declarou que sua mãe era dona de casa, artesã e trabalhou intensamente no movimento de assistência social da ação católica em Aracaju, ressaltando também que no período em que estudou no Colégio São José, em Aracaju, o espírito Humanista das irmãs franciscanas teve muita influência em sua formação, pois as irmãs estavam sempre muito envolvidas em causas sociais, incentivando as alunas a perceberem "o sofrimento do povo". Outra Deputada do estado destacou que seu "espírito de solidariedade" foi influenciado pelo trabalho social que sua mãe desenvolvia em seu bairro, que buscava ajudar futuras mães carentes com enxovais para os recém-nascidos. Também um Vereador apontou que cresceu vendo seu pai desenvolvendo atividades no campo social, através da alfabetização informal de crianças e adultos.

Em dois casos a forte presença de políticos na família foi fator determinante na entrada na vida política. Uma Deputada é "herdeira política", seu pai foi Deputado Estadual entre os anos de 1987 e 1995 e quanto aos seus irmãos, um foi prefeito de Itabaiana (SE) e outro Deputado Estadual e Federal de Sergipe. Já o outro Deputado Estadual diz que se envolveu com a política partidária a partir do envolvimento político da família de sua esposa.

Notou-se também que o investimento na escolarização é uma marca do itinerário desses políticos. Em apenas um caso, o po- 
lítico possui somente graduação, sendo que cinco deles realizaram pós-graduação (em nível de especialização ou mestrado) e um realizou duas graduações. Porém, percebeu-se que o investimento na escolarização superior talvez não tenha sido o fator determinante no sucesso da carreira política, mas um recurso que combinado a outros possibilitou com que esses professores ascendessem profissionalmente ${ }^{13}$.

Quanto a formação acadêmica dos políticos estudados foi possível perceber que somente uma Deputada Estadual realizou sua graduação em uma Instituição Superior Privada, sendo que a socialização universitária dos outros políticos aconteceu em Universidades Públicas; portanto, em espaços sociais que apresentam contextos semelhantes, bem como em períodos próximos e em uma época política historicamente marcada por um regime autoritário (anos setenta) o que possibilita inferir sobre como tal contexto pode ter sido formador de "opiniões e práticas simbólicas" que os distinguem de outros indivíduos, como sugere Bourdieu (1996). Após realizar a licenciatura em Construção Civil, em tempos mais recentes, o Vereador de Aracaju cursou Direito em uma instituição privada em Aracaju, porém em um novo contexto social e político. Devo destacar também que o único Deputado Federal ${ }^{14}$, por ser o mais jovem do grupo, tem uma socialização acadêmica em um período diferente do restante, os anos noventa.

O período em que estiveram no Ensino Superior é destacado por quatro (4/7) políticos como um momento muito importante em seus itinerários. As narrativas de experiências no espaço uni-

130 aumento e a diversificação da titulação escolar têm sido apontados como probabilidade de sucesso em carreiras políticas, em que a mobilização de títulos, experiências e saberes acadêmicos ou científicos são acionados na tentativa de ocupação a cargos de interesse. (Seidl, 2009).

14 A média etária de seis políticos estudados é de 58 anos, somente o professor eleito a Deputado Federal está bem abaixo da média, com 42 anos. 
versitário são apontadas como centrais à aquisição de conhecimentos específicos da profissão, como também é a partir deste contexto que disseram passar a ser sensibilizados à participação política. Destaco que está presente no itinerário acadêmico de alguns políticos a participação no movimento estudantil (4/7), e o reconhecimento por parte deles de que foi na universidade que passaram a perceber e compreender a realidade social e política, em âmbito local e também nacional.

Desta forma, a partir da análise sobre a origem social e a escolarização dos políticos professores é possível identificar características em comum entre eles, principalmente no que se refere ao percurso escolar e acadêmico, pois a maioria apresenta uma socialização escolar semelhante, sendo desenvolvida em espaços de Ensino Público e em um contexto histórico aproximado. Isto pode significar um fator importante na aquisição de um capital cultural que favoreceu a entrada deles no espaço político. Além de todos terem Ensino Superior, eles continuaram investindo na sua formação acadêmica, o que permitiu com que agregassem aos seus itinerários conhecimento formal e saberes específicos da profissão que desempenhavam.

\section{Modalidades de carreiras políticas}

Além de o magistério ser apontado na literatura sobre o tema (CORADINI 2001, RODRIGUES 2006), como uma atividade de fácil conciliação com outras, é também na profissão que se ampliam as redes de relações, possibilitando com que os profissionais da educação consigam bons apoios em sindicatos, associações e diretórios estudantis nos quais podem sustentar suas possíveis aspirações eleitorais, como prováveis representantes destes setores. Como o magistério é um meio profissional com grande número de membros, isto pode sugerir aos candidatos professores que tenham maiores chances de conquista de apoio ou votos para ocupação de cargos eletivos ou não. 
Esta pesquisa revelou que o grupo estudado pode ser apresentado através de dois padrões de políticos: um grupo com professores que não estiveram ligados a quaisquer tipos de movimento social durante seus trajetos profissionais e outro grupo com os professores que além de terem assumido cargos políticos também tiveram algum tipo de participação em movimentos sociais (sindicatos, associações e estudantil), o que implica no acúmulo de capital militante.

O primeiro grupo é composto por dois políticos (2/7) que apresentam em seus itinerários características muito similares. Além de os dois não terem se envolvido com movimentos sociais, eles ocuparam cargos de indicação política antes de serem eleitos pela primeira vez, um como Vereador de Aracaju e o outro como Deputada do estado de Sergipe. Em ambos os casos, o envolvimento da família na política também é uma característica de capital social de ambos, mesmo que com uma influência mais forte em um dos casos.

0 primeiro exemplo é da pedagoga e Deputada Estadual de Sergipe, ela assumiu vários cargos administrativos na área da Educação, na prefeitura de Itabaiana (SE), entre 1977 e 1982, por influência política de seu pai e de seus irmãos, tanto no município quanto no Estado. Também assessorou seu pai na Assembleia Legislativa de Sergipe, quando ele foi Deputado Estadual, entre os anos de 1987 e 1995. Por isto, a Deputada considera que sua aproximação com a política aconteceu de forma "natural e espontânea", pois, segundo ela, desde sua infância teria acompanhado as "questões políticas" de seu município, juntamente com a família. Após um longo percurso em cargos administrativos e na assessoria parlamentar de seu pai, a Deputada assumiu o que chama de "herança política" e que resultou em conquistas consecutivas de cargos eletivos. Ela se candidatou pela primeira vez em 1994, sendo eleita Deputada Estadual aos 40 anos. Em 2004 foi eleita prefeita do município de Itabaiana e depois voltou para Assembleia Legislativa de Sergipe, onde permanece até os dias atuais como Deputada do Estado. 
O segundo exemplo, deste grupo, é um professor de Química, empresário da educação e Deputado Estadual. Assumiu cargos políticos importantes em secretárias do Estado entre os anos de 1987 e 1990, e em 1996 foi eleito pela primeira vez Vereador de Aracaju, aos 43 anos. Em 1998, concorreu a uma vaga como Deputado Estadual, sendo eleito. 0 Deputado ressaltou, em entrevista, que após a primeira vez que foi eleito, em 1996, não deixou mais de assumir cargos eletivos, destacando que sua primeira eleição é devida aos alunos e pais de alunos de suas escolas, e que tinha a noção que representava "milhares de alunos" que confiaram em seu trabalho, dizendo que este foi o "empurrão" fundamental para ele estar na política há aproximadamente 20 anos. É importante ressaltar que além deste "empurrão", só seis anos depois de ter ocupado seu primeiro cargo político como secretário $^{15}$, é que foi eleito pela primeira vez. Tal investimento na política também corresponde ao crescimento de seu sucesso empresarial na educação.

O segundo grupo, composto por cinco professores/políticos (5/7) apresenta em seus itinerários o envolvimento e a participação em diferentes movimentos sociais. Duas professoras estudadas são exemplos de militância profissional, que dizem reforçar seus interesses de transformação social a partir do engajamento associativo e sindical, e em nome da profissão; uma na associação dos professores do município de Aracaju e a outra na associação dos professores do estado de Sergipe.

A professora e Deputada Estadual representante da categoria profissional no Estado, além de exercer atividade docente, assumir coordenações pedagógicas e desenvolver projetos na área da educação em Aracaju e em Sergipe, foi eleita presidente do SIN$\mathrm{TESE}^{16}$ em 1992. A professora esteve na presidência do sindicato

15 Na Secretaria de Estado do Trabalho.

16 Sindicato dos Trabalhadores da Educação de Sergipe. 
no período entre 1992 e 2000, ora como presidente ora como vice. Em 2001 assumiu a Secretaria Municipal de Educação de Aracaju e em 2002 foi eleita, pela primeira vez, a Deputada Estadual, cargo em que permanece até os dias atuais. A participação e o envolvimento da professora apresentam um exemplo claro de investimento político, orientado pela lógica militante voltada, segundo ela, principalmente para a profissão, a educação e a qualidade de ensino.

Outro exemplo é de uma professora e Vereadora de Aracaju que militou no movimento sindical da categoria desde os anos de 1985, exclusivamente no SINDIPEMA ${ }^{17}$, assumindo a direção do sindicato em 1989, onde permaneceu até o ano de 2003. A professora assumiu a Secretaria Municipal de Educação de Aracaju em 2002 e concorreu pela primeira vez a uma vaga como vereadora em 2004, ficando suplente e assumindo a cadeira em 2006, sendo reeleita em 2008.

Nos dois casos, as professoras são aposentadas na rede pública de ensino, uma pelo município e a outra pelo estado. 0 exemplo de itinerário profissional e militante de ambas confirma o que sugere Rodrigues (2006), que a prática sindical é uma boa alternativa de inserção na política eleitoral. Acrescento que, neste caso, quando a situação favorável de um partido ou coligação à qual se está filiado assume o Governo, abrem-se as possibilidades de ocupação de cargos e o caminho para as disputas eleitorais se torna uma forma de manutenção na política. Como afirma Coradini (1995 e 2008), a mobilização de recursos associativos representa um tipo de capital social que pode ser encontrado nos percursos de acesso ao poder político de dirigentes e representantes partidários, e isto pode ser entendido como uma forma para se estabelecer redes sociais e organizações de representação coletiva ligada a interesses e questões sociais específicas. 
Em outros dois casos, deste mesmo grupo, estão presentes o envolvimento em uma associação de moradores de bairro e o engajamento em uma associação educacional. 0 professor e também Vereador de Aracaju relatou que seu envolvimento e inserção na política eletiva partiram de seu engajamento com a Associação de Moradores, e que vem assumindo sucessivamente uma cadeira na Câmara de Vereadores desde as eleições de 1988. Sua inserção na política pode ser comparada com o que Barreira (1998) denomina de "candidaturas populares", em que a apresentação dos candidatos consiste nos trabalhos realizados no local de sua moradia, onde a experiência com associações de moradores funciona como espécie de "iniciação prévia e necessária para o desempenho da representação nos espaços institucionais da política" (BARREIRA, 1998, p.14). Destaco também que o Vereador nunca se candidatou a outros cargos eletivos, permanecendo na vereança durante 24 anos.

O outro caso é de uma professora de Geografia e Deputada Estadual que destacou, em entrevista, que foi através de seu trabalho desenvolvido em uma Associação Educativa, em Japaratuba (SE), durante um período de 20 anos, em que passou a assumir cargos políticos naquele município, porém ela ressaltou que o período em que morou em uma comunidade espiritualista, em Aracaju, serviu como um laboratório, que propiciou e facilitou sua compreensão sobre as relações humanas e lhe oportunizou adquirir experiência para trabalhar com diferentes tipos de políticas públicas, o que foi aprimorando com as funções políticas que foi ocupando. Após assumir cargos políticos no município, a Deputada assumiu a diretoria do PT no estado, sendo lançada a vereadora de Aracaju nas eleições de 2000, aos 46 anos. A professora ficou suplente e logo assumiu o cargo, sendo reeleita em 2004, após assumir cargos políticos na prefeitura de Aracaju. Em 2006, foi eleita Deputada Estadual, permanecendo no cargo até os dias atuais.

Tais professores revelam em seus itinerários combinações de recursos que se converteram em experiência política. Com habili- 
dades e competências consideradas essenciais para a entrada no jogo político, esses profissionais passaram a ser reconhecidos publicamente a partir de suas ações de engajamento e militância múltipla que, consequentemente, os conduziram a cargos políticos com importante representatividade no município de Aracaju.

Rodrigues (1997) indica que os sindicatos e associações são espaços de socialização política para homens e mulheres, pois os levam à "conscientização política", isto é, através da aquisição e expansão do capital militante, passam a entender como atuar na política. Esta afirmação é destacada na fala de uma professora e deputada estadual, que ressaltou que o sindicato é "mais um" lugar de conscientização e politização de professores. Reforçando esta ideia, outra professora e vereadora declarou que foi no sindicato da categoria que desenvolveu sua "conscientização política", pois foi neste espaço que ela passou a compreender o funcionamento do jogo político e analisar como poderia utilizar seus conhecimentos também na politização de alunos do magistério. 0 engajamento associativo e sindical funcionou como o principal recurso que lhes possibilitou atuar politicamente em nome da categoria, qualificando-as e legitimando-as na conversão e inserção no campo político.

O quinto caso deste grupo é caracterizado pelo envolvimento no movimento estudantil e a militância partidária A participação em movimento estudantil, neste caso, como Presidente do Diretório Central dos Estudantes, foi um recurso que abriu possibilidades para que ele ingressasse na vida política, permitindo-lhe adquirir habilidades que também lhe possibilitaram ascender politicamente, tal participação esteve presente em outros itinerários deste grupo. 0 professor de Biologia e Deputado Federal, após a sua militância no movimento estudantil e no Partido dos Trabalhadores, assumiu cargos importantes dentro do partido e cargos políticos na prefeitura de Aracaju e no governo do Estado. Foi candidato pela primeira vez nas eleições de 2010, aos 39 anos, sendo eleito. 
O movimento estudantil passa a ser apontado, ainda, como um recurso importante de acesso para o campo da política. No caso estudado, a militância estudantil conjugada a militância partidária formaram uma base que foi considerada legítima para a aquisição de um capital político que permitiu sua ascensão dentro do próprio partido e a outras esferas da política.

Vale destacar que os cinco casos (5/7) que apresentam envolvimento com movimentos sociais (associações, partidos e sindicatos) são do Partido dos Trabalhadores. Os estudos de Glaglietti (2003), Marenco \& Serna (2007) e Rodrigues (2006) apontam que uma das características do Partido dos Trabalhadores é o vínculo com associações da sociedade civil que representam interesses coletivos como o sindicalismo de trabalhadores e movimentos estudantis ou organizações que representam questões sociais.

Com o resultado das eleições de 2008 para as prefeituras do Estado, foi possível identificar que os professores eleitos, em sua maioria, também eram do Partido dos Trabalhadores. No total de 43 professores eleitos nas prefeituras de Sergipe 9 deles são do PT, em seguida vem o PMDB com 4 professores e em terceiro o PP com 4 professores eleitos ${ }^{18}$. Este resultado confirma o que Rodrigues (2006) também observou na Câmara Federal quanto às profissões e as filiações em partidos, em que os professores também se apresentam em maior número como eleitos pelo Partido dos Trabalhadores.

18 PDT/PSC/PSDB/PTB tiveram 3 professores eleitos de cada partido; PV/PSB/PPS 2 professores eleitos por partido e PR/PCdoB/PTC/PRP/DEM/PHS/PTdoB 1 professor eleito por partido. Fonte: Tribunal Superior Eleitoral. 


\section{Considerações finais}

Com o intuito de realizar uma análise que priorizasse as diferentes dimensões da vida social, apresentei no decorrer deste artigo alguns aspectos de socialização dos políticos pesquisados, que me permitiram perceber como eles adquiriram competências que propiciaram saberes específicos para ocuparem cargos eletivos, bem como construíram seus itinerários e afirmaram representar politicamente uma categoria profissional específica.

Procurei realizar uma análise sobre o processo de participação e envolvimento de tais professores com a política que, posteriormente, foi mediada pela legitimação profissional e conjugada a um conjunto de saberes que foram sendo acionados em contextos específicos e estratégicos para a aquisição de um capital militante. Noto que elementos sociais e culturais de seus itinerários podem ser definidos como uma forma eficaz de promoção de suas ações, o que pode lhes garantir notoriedade e distinção num constante jogo de negociação política. As atividades realizadas no decorrer dos mandatos são estrategicamente organizadas para que sejam reeleboradas as formas de se manter contato com os eleitores. Por isso, acompanhei, mesmo que parcialmente, diferentes rotinas da vida dos políticos. Foi preciso observar atividades nos gabinetes, sessões parlamentares, eventos promovidos, mas também os recursos de comunicação pelos quais dizem quem representam.

A partir das entrevistas realizadas, conjugadas a outros materiais de análise, pude observar até que ponto a declaração de uma ocupação no cadastro do TSE tem relação com a representação política de determinada categoria. Embora os professores/políticos apresentem um trajeto profissional embasado no exercício docente ou escolar, percebi que as funções foram desempenhadas de formas muito variadas por cada um deles, o que não impediu que fosse possível perceber semelhanças em 
vários aspectos presentes em seus itinerários, que os tornaram aptos a entender o sentido do jogo político.

A participação em movimentos sociais, iniciado ainda no movimento estudantil, descrito no itinerário de 4 (4/7) professores possibilitou uma socialização política que contribuiu para a aquisição de "saberes" iniciais essenciais. 0 envolvimento e engajamento em associações presentes no itinerário de 2 (2/7) professores; bem como a atuação no sindicato dos professores, como relatado por 2 (2/7) professoras, são fortemente marcados como determinantes na condução à política eletiva. 0 envolvimento em movimentos sociais presente no itinerário desses políticos possibilitou esboçar algumas das características em comum no contexto estudado.

Embora seja possível identificar outras semelhanças entre o grupo, como, por exemplo, socialização familiar e política favorável presente no itinerário de 3 (3/7) Deputados Estaduais, cada profissional apresentou um percurso próprio de inserção e ascensão na carreira docente, que possibilitou a apreensão de como as competências e as habilidades foram adquiridas neste período, e que foram sendo ressaltadas no decorrer da atuação profissional. Dos sete políticos estudados, tivemos um caso que apresentou a herança política familiar como determinante, credenciando uma Pedagoga a assumir a função política que seu pai desempenhava no Estado. A profissão, no caso desta professora, parece ter sido um instrumento a mais, pois também através dela adquiriu habilidade técnica para assumir cargos administrativos, o que concedeu mais visibilidade e possibilitou ampliar suas relações, antes de partir para disputas eletivas. Destaco que a Deputada ocupou seu primeiro cargo político, muito antes de sua formação como pedagoga.

A partir das análises realizadas foi possível identificar duas modalidades de carreira política: uma modalidade composta por cinco (5/7) professores oriundos de movimentos sociais; e a outra modalidade caracterizada por dois (2/7) professores com 
influência política familiar. As modalidades apresentam também outra característica comum, o grupo que faz parte dos movimentos sociais é composto por políticos filiados ao Partido dos Trabalhadores (5/7) e o outro grupo composto por políticos filiados ao Partido Socialista Brasileiro (1/7) e Democratas (1/7).

Destaco que, embora duas professoras apresentem militância no sindicato da categoria, e isto foi fator determinante para suas inserções na política eletiva, outros fatores da socialização caracterizam de forma específica e diferenciada suas experiências, politização e disposições ao engajamento militante. Sendo que uma é oriunda de uma família humilde, pai analfabeto e mãe pouco escolarizada, e diz que foi preciso trabalhar desde muito cedo para ajudar nas despesas domésticas; a outra é de origem familiar com condições favoráveis, pais escolarizados e família politizada e viu a partir da prática social realizada pela família a necessidade de "lutar por uma educação de qualidade". 0 traço comum é o longo itinerário militante voltado à profissão.

Outra constatação é que, a partir do ensino universitário, 6 dos 7 políticos passaram pelo mesmo espaço de socialização em um mesma época, a Universidade Pública Federal. Um local de interação que lhes permitiu vivenciar o contexto das transformações sociais e políticas de transição da Ditadura Militar para a Abertura Democrática. Foi um momento de efervescência de debates e ações com os quais todos disseram terem se envolvido, por manifestações favoráveis à redemocratização do País. Condição que pode ter contribuído de forma significante no desenvolvimento pelo "gosto" por assuntos políticos, ou ainda, permitiu com que eles vivenciassem experiências importantes a sua formação pessoal como "jovens contestadores". Dos 7 políticos estudados, 5 deles ressaltaram suas participações no movimento contra a Ditadura Militar.

Sabe-se que as formas de construção da carreira política variam de acordo com os recursos individuais de cada um. São combina- 
ções de recursos sociais, culturais, profissionais e políticos, que têm como base a diversidade das relações sociais, que se convertem em competências próprias da esfera política. Mesmo assim, foi possível identificar algumas características mais gerais presentes nos itinerários estudados, como: atuação profissional intensa, engajamento militante e escolarização elevada.

Para concluir, ressalto que há uma dimensão simbólica que parece ser explorada pelos políticos quando se trata de lembrarem do fato de serem professores. Em alguns momentos, eles ressaltam a ideia de compromisso social, de preocupação com a Educação, com a cultura e com as crianças e jovens; qualificativos associados corriqueiramente à profissão. Mesmo que a representação política de alguns deles não esteja exclusivamente relacionada à categoria profissional, a ocupação é somada às outras classificações como fator positivo na disputa de cargos eletivos. Destaco que todos os casos estudados recorreram à profissão de professor durante o mandato ou em época de campanha eleitoral, como forma de ampliarem seus recursos no jogo político.

\section{Referências bibliográficas}

BARREIRA, Irlys. Chuva de papéis: ritos e símbolos de campanha eleitorais no Brasil. Rio de Janeiro: Relume-Dumará, 1998.

BEZERRA, M. Em nome das "bases". Política, favor e dependência pessoal. Rio de Janeiro: Relume-Dumará, 1999.

BOURDIEU, P. Espaço Social e espaço simbólico. In: Idem. Razões práticas: sobre a teoria da ação. Campinas: Papirus, 1996, p.13-28.

O poder simbólico. 2ª Ed. Rio de Janeiro: Bertrand Brasil, 1998.

Os Três Estados do Capital Cultural. In: NOGUEIRA, M. \& CATANI, A. Escritos da Educação. Petrópolis: Vozes, 1998, p. 73-79.

BRZEZINSKI, Iria. Pedagogia, pedagogos e formação de professores: busca e movimento. Campinas: Papirus, 1996. 
BRZEZINSKI, Iria (Org.). Profissão professor: identidade e profissionalização docente. Brasília: D. F. Editora Plano, 2002.

CORADINI, O. L. (Org.) Estudos de grupos dirigentes no Rio Grande do Sul: algumas contribuições recentes. Porto Alegre: Editora da UFRGS, 2008.

Em nome de quem? Recursos sociais no recrutamento de elites políticas. Rio de Janeiro: Relume Dumará: UFRJ, Núcleo de Antropologia da Política, 2001.

Relações Profissionais e Disputas Eleitorais. In: BARREIRA, Cesar \& PALMEIRA, Moacir. Política no Brasil. Visões de Antropólogos. Rio de Janeiro: Relume Dumará, 2006.

Engajamento Associativo/Sindical e Recrutamento de Elites Politicas: "empresários" e "trabalhadores" no período recente no Brasil. In: Antropolítica: Revista Contemporânea de Antropologia e Ciência Política. Niterói: Ed.UFF, 1995.

. Escolarização, Militantismo e Mecanismos de "Participação" Política. In: HEREDIA, Beatriz, TEIXEIRA, Carla, BARREIRA, Irlys (orgs.). Como se fazem eleições no Brasil. Rio de Janeiro: Relume-Dumará, 2002.

DOGAN, M. Les Professions Ppropices à La Carrière Politique: osmoses, filieres et vivieres, 1999. Disponível em: http://www.docstoc.com/ docs/56209835/Professions-adja_antes.

EVANS-PRITCHARD, E. Algumas reminiscências e reflexões sobre o trabalho de campo. In. Bruxaria, Oráculos e Magia Entre os Azande. RJ: Jorge Zahar Editor, 2005.

FIGUEIREDO, Taís C. S. Em nome dos professores? Inserção profissional e carreiras políticas. Dissertação (Mestrado em Antropologia). Universidade Federal de Sergipe. São Cristóvão, 2012.

GAGLIETTI, M. PT: ambivalências de uma militância. Porto Alegre: Palmarinca, 2003.

GAXIE, D. Économie des Partis et rétributions du militantisme. Revue Française de Science Politique, n. 1, v. 27, 1977.

GEERTZ, C. A interpretação das culturas. Rio de Janeiro: LTC - Livros Técnicos e Científicos Editora S.A, 1989.

o saber local: novos ensaios em antropologia interpretativa. Petrópolis, RJ: Vozes, 1997.

HEREDIA, B. Entre duas eleições. Relação político-eleitor. In. HEREDIA, B. TEIXEIRA, C. \& BARREIRA, I. Como se Fazem Eleições no Brasil. RJ: Relume-Dumará, 2002. 
KUSCHNIR. K. Eleições e representação no Rio de Janeiro. Rio de Janeiro: Relume Dumará: UFRJ, Núcleo de Antropologia da Política, 1999.

Antropologia e política. Revista Brasileira de Ciências Sociais. Vol. 22 no .64, 163-167. São Paulo, 2007. Disponível em: http://www.scielo. br/scielo.php?script=sci $\quad$ arttext\&pid=S0102-69092007000200014\&la ng=pthttp://www.scielo.br/scielo.php? script=sci arttext\&pid=S0102-69092007000200014\&lang=pt

o Cotidiano da Política. Rio de Janeiro: Jorge Zahar Ed. 2000.

KUSCHNIR. K. \& CARNEIRO. L. P. As dimensões subjetivas da política: cultura política e antropologia da política. Estudos Históricos, Rio de Janeiro, v. 13, n. 24, 1999.

MARENCO, A \& SERNA, M. Por que carreiras políticas na esquerda e na direita não são iguais: recrutamento legislativo em Brasil, Chile e Uruguai. Revista Brasileira de Ciências Sociais. Vol. 22 n 64, junho/2007, p. 94-194.

MATONTI, F. \& POUPEAU, F. O Capital militante: tentativa de definição. Texto traduzido por SEIDL, Ernesto. Do original: Le capital militant. Essai de définition. Actes de la recherche en sciences sociales, 2004, n.155, p. 4-11. (Tradução não publicada)

MENEZES. Ana. Entrevista concedida à Taís C. S. Figueiredo. Aracaju, 2011.

NÓVOA, A. Profissão Professor. Porto/PT: Porto Editora, 1999.

NUNES, Maria Thetis. História da Educação em Sergipe. Paz e Terra. Governo do Estado de Sergipe: UFS, 1984

OLIVEIRA, W. Engajamento Político, Competência e Elites Dirigentes do Movimento Ambientalista. Revista de Sociologia e Política, v. 16, 2008. p. 167186.

PALMEIRA, M \& GOLDMAN, M. Antropologia, voto e representação política. Rio de Janeiro: Contra Capa Livraria, 1996.

PETRARCA, F. “Direitos Humanos se conquistam na luta": igualdade racial, ativismo jurídico e defesa de causas coletivas no Rio Grande do Sul. 2011. Disponível em: http://www.scielo.br/scielo.php?pid=S0102$\underline{-69922011000100008 \& \text { script}=s c i \text { arttext }}$

. Jornalismo como Profissão: recursos sociais, titulação acadêmica e inserção profissional dos jornalistas no Rio Grande do Sul. 2007, 308f. Tese de Doutorado em Sociologia. Programa de Pós Graduação em Sociologia, UFRGS, Porto Alegre, 2007. Disponível em: http://www.lume.ufrgs.br/bitstream/handle/10183/10761/000601473. Pdf?sequence=1. 


\section{Taís Cristina S. Figueiredo}

RIBEIRO, Maria L. S. A Formação Política do Professor de 1‥ E 2. Graus. São Paulo: Cortez, 1984.

RODRIGUES, Leônico Martins. Mudanças na Classe Política Brasileira. São Paulo: SP: Publifolha, 2006.

ROMANELLI, Otaíza de Oliveira. História da educação no Brasil. 28 ed. Petrópolis: Vozes, 2003.

SANTOS. V. Antropologia do cotidiano da política: o gabinete parlamentar. Monografia (Curso de Ciências Sociais). Universidade Federal de Sergipe. São Cristóvão, 2009.

SAVIANI, Dermeval. O legado educacional do século XX no Brasil. Campinas, SP: autores associados, 2004;

SEIDL, E. Disposições a militar e lógica de investimentos militantes. Pro-Posições: Dossiê Educação e Política: novas configurações nas práticas de militância. Universidade Estadual de Campinas. Faculdade de Educação Campinas-SP. V. 20, n. 2. 2009.

. Elites militares, trajetórias e redefinições político-institucionais (18501930). Revista de Sociologia e Política. Vol. 16, no 30: 199-220. Jun 2008.

SILVA, Ronaldo A. P. Do Mestre Escola à Normalista: Profissionalização do Magistério em Sergipe (1870-1910). Revista da Fapese. Vol. 4, n 1: 89-112. Jan/ Jun 2008. Disponível em: http://www.fapese.org.br/revista fapese/v4n1/artigo9.pdf

TANURI, L. M. História da formação de professores. Revista Brasileira de Educação, n. 14, p. 61-88, mai./jun./jul./ago. 2000

WEBER, Max. Ciência e Política: duas vocações. São Paulo: Cultrix, 2008.

Recebido em 02.03.2013

Aprovado em 23.05.2013 
